\title{
DIGNIDADE DA PESSOA HUMANA E O DÉCIMO SEGUNDO CAMELO - SOBRE OS LIMITES DA FUNDAMENTAÇÃO DE DIREITOS ${ }^{1}$
}

Emil Albert Sobottka*

RESUMO - dignidade da pessoa humana adquiriu em anos recentes um destaque como princípio fundamental a partir do qual são derivados direitos, considerados igualmente fundamentais. Com base na discussão provocada por Luhmann sobre recursos externos ao direito num sistema definido como operativamente fechado e cognitivamente aberto, o texto discute se a dignidade da pessoa humana consegue ocupar este lugar funcional.

PALAVRAS-CHAVE - Dignidade da pessoa humana. Direitos fundamentais. Sociologia jurídica. Teoria sistêmica.
ABSTRACT - The dignity of the human being has gained prominence in recent years as a fundamental principle from which rights also considered fundamental are derived. Based on the discussion provoked by Luhmann on external resources to the right in a system defined as operatively closed and cognitively open, the paper asks if the dignity of human being may occupy this functional place.

KEY WORDS - Human dignity. Fundamental rights. Legal sociology. Systems theory.

A Constituição Federal do Brasil tem como título de sua primeira seção "Dos princípios fundamentais", e nela é definido que a República Federativa do Brasil assume para si a dignidade da pessoa humana, juntamente com a soberania, a cidadania, os valores sociais do trabalho e da livre iniciativa e o pluralismo político, como seus fundamentos (Art. $1^{\circ}$ ). Mas o que são estes fundamentos, de onde vêm e que os torna vinculantes?

Segundo Comparato (1998), a noção de fundamento ocupa o lugar de uma razão justificativa para a questão por que uma norma vale e deve ser

Doutor em Sociologia e em Teologia pela Universidade de Münster, Professor nos Programas de Pós-Graduação em Ciências Criminais e Ciências Sociais da PUCRS.

1 Este estudo centra-se numa recepção do artigo Die Rückgabe des 12. Kamels, de N. Luhmann (2000), e na reação de Gunther Teubner e Peer Zumbansen (2000) e de Marcelo Neves (2004).

\begin{tabular}{|l|l|l|l|l|l|} 
VERITAS & Porto Alegre & v. 53 & n. 2 & abr./jun. 2008 & p. 107-119
\end{tabular}


cumprida. Ela seria o substituto da noção grega de princípio; a referência deixa de ser a busca da origem, para situar-se no plano ético, da base normativa. No pensamento moderno, onde generaliza-se a recusa a aceitar o recurso a uma autoridade sobrenatural para a fundamentação ética do agir humano, foi percebida a necessidade de encontrar equivalentes funcionais àquela autoridade. Mas a quem recorrer substitutivamente? O jusnaturalismo e o positivismo jurídico foram respostas alternativas para esta questão: o primeiro recorre ao reconhecimento tácito da autoridade dos fatos naturais, enquanto o segundo entrona diante de si uma concepção de liberdade para a autonomia. Ambos arquitetam com este recurso uma ordem social correspondente. Direitos, deveres e expectativas normativas são derivados deles.

Recentemente, em especial desde meados do século 20, declarações de direitos humanos, constituições nacionais e mesmo a operação concreta do direito em muitos países acolheram a dignidade da pessoa humana como um novo fundamento ou princípio tido como capaz de orientar normativamente o agir humano (cf. Häberle, 2005).

O autor a quem se tributa a formulação da singularidade do homem e a dignidade humana como o fundamento ético é Kant, quando diz na Metafísica dos costumes (1977): "No reino dos fins, tudo tem um preço ou uma dignidade. Aquilo que tem um preço, em seu lugar também pode ser colocado algo diferente como equivalente; mas o que, ao contrário, está acima de qualquer preço e, portanto, não permite equivalente, isto tem dignidade". O ser humano se distingue e sobressai dentre os outros seres vivos porque, como espécie e como indivíduo dentro dela, não tem preço e sim dignidade; ele é incomparável e não pode ser usado como meio para outros fins.

Comparato (1998) busca ampliar esta posição de destaque da dignidade da pessoa humana e para fundamentá-la usa um argumento que segue uma linha claramente dedutiva: "se o direito é uma criação humana, o seu valor deriva, justamente, daquele que o criou. O que significa que esse fundamento não é outro, senão o próprio homem, considerado em sua dignidade substancial de pessoa, diante da qual as especificações individuais e grupais são sempre secundárias". A aparência de simplicidade e de autoevidência deste novo princípio fundamental se desfaz tão logo se observa as discussões sobre ele e os múltiplos casos limítrofes em que sua efetivação não permite decisões unívocas ${ }^{2}$.

No presente texto, porém, não se pretende discutir nem a validade da fundamentação de direitos na dignidade da pessoa humana e a derivação de direitos e deveres a partir dela, nem os "casos difíceis" de sua eventual aplicação no cotidiano. Pretende-se, ao contrário, tomar um pouco mais de distância e observar dois movimentos inerentes à fundamentação de direitos: o recurso a pressupostos "últimos", externos e insubordináveis ao processo

2 Para uma boa visão, cf. os textos reunidos em Sarlet (2005) e Tiedemann (2006) 
argumentativo, e a necessidade que, ao fim e ao cabo se tem, de acomodar conflitos entre direitos e ou princípios fundamentais. Na primeira parte, será tomada como base uma discussão incitada por Luhmann a partir de uma parábola sobre a repartição de uma herança, seguida do que ele e Teubner vêem como a visão da sociologia jurídica. Por fim, serão acolhidos brevemente as reflexões críticas de Franz Hinkelammert (1985) sobre os critérios de decisão entre direitos humanos na democracia e as de Marcelo Neves sobre a heteronomia do sistema jurídico em sociedades de modemidade periférica.

1.

Há uma reivindicação clara no pensamento moderno que é a de não depender de recurso externo, de ser sujeito autônomo e, ao ser autônomo, ser livre. Na resposta à pergunta o que é iluminismo/esclarecimento, Kant (1988) descreve magistralmente esta postura. Se num primeiro momento a externalidade recusada era Deus e os que se proclamavam seus representantes, o recurso jusnaturalista à natureza só limitadamente cumpria o requisito da imanência. No positivismo, a auto-nomia é radicalizada e a produção legítima de normas passa a legitimar as normas produzidas - ao preço da perda de toda e qualquer referência capaz de legitimamente poder deslegitimar a lei ${ }^{3}$. O recente recurso à dignidade da pessoa humana como o/um princípio fundamental para direitos humanos, direitos fundamentais e também para direitos subjetivamente definidos consagra o retorno da possibilidade, em novo plano, de recorrer a uma autoridade para transformar reivindicações em expectativas normativas legítimas. A questão, no entanto, é se a dignidade da pessoa humana neste contexto é um critério externo, que torna a legitimação heterônoma, se é tão somente um catalisador que com sua mera presença viabiliza uma formação discursiva sem participar diretamente do direito, ou se é um elemento factual dado e, por conseguinte, um recurso puramente interno. Quero aprofundar esta reflexão à luz da parábola do décimo segundo camelo, trazida por Luhmann (2000).

Luhmann começa o texto referido contando a parábola. Um beduíno de muitas posses fixou em seu testamento a divisão dos seus bens - basicamente os camelos - entre os três filhos homens. Seguindo o costume, determinou que o mais velho deveria receber a metade dos animais; o segundo receberia um quarto e o terceiro um sexto. Ainda que esta repartição possa parecer injusta à luz da prática atual no Ocidente, ela não só correspondia aos costumes, mas também à valorização proporcional dos

3 Os horrores praticados pelo regime nacional-socialista são exemplo extremo e plástico, mas não esgotam este risco; o próprio temor da ditadura das maiorias nas democracias, embora originalmente expressão da desconfiança dos liberais quanto à possibilidade de generalização de uma sociedade de iguais, revela lugares menos evidentes da presença deste risco. 
filhos, resultante da alegria de seu pai pelo nascimento de um varão que levaria seu nome adiante. As circunstâncias, no entanto, levaram a que o número de camelos tivesse diminuído a ponto de, quando da morte do beduíno, restarem apenas 11 camelos. Como não havia como cumprir a regra na íntegra e não houve acerto entre as partes, a questão foi levada ao Cadi, o tribunal local. O juiz fez aos litigantes a seguinte oferta: colocaria à disposição dos irmãos um dos seus camelos, e determinou: Se Alá assim o permitir, devolvam-no tão logo for possível. Agora com doze camelos, a divisão do testamento tornou-se fácil: o mais velho recebeu os seis; o segundo, os três e o terceiro, os dois que lhe correspondiam - tudo segundo a determinação do pai. E os 11 camelos da herança estavam distribuídos.

Nesta operação do sistema, o camelo que permitiu uma divisão legítima do legado paterno daqueles irmãos é simultaneamente supérfluo e indispensável. Sem ele seria impossível fracionar adequadamente os animais, mas como o testamento não abrangia a totalidade dos bens, sua presença foi performativa para a solução do conflito, ao final do qual ele restou excedente. Luhmann refere no texto questões interessantes como: ele será devolvido em atendimento à determinação do juiz? Ele pode ser devolvido? $\mathrm{E}$ se alguém contestar a decisão, como refazer o processo se o décimo segundo camelo não estiver mais à disposição?

Segundo o autor, "cada operação do sistema precisa apoiar-se em pressupostos que não podem ser questionados na e nem criados pela própria operação". Com isso os pressupostos - aqui o décimo segundo camelo - sugerem uma determinação que de fato não existe. Empréstimo e devolução simbolizam esta ambivalência: eles são uma premissa capturada para as decisões do sistema, considerado operativamente fechado em relação ao entorno, mas que ao mesmo tempo precisa operar com premissas flutuantes para evoluir.

Segundo Luhmann, o próprio Direito é constituído assim paradoxalmente - e de forma diferente para o sistema e para o observador externo. Um observador interno vê no sistema uma relação entre regra e decisão. A fixação textual das regras sugere que seja possível distingui-las das decisões. Fixadas textualmente, elas se tornam objeto de decisões tomadas segundo regras que, quando fixadas textualmente, podem tornar-se igualmente objeto de decisão. Assim, regra e decisão se pressupõem e se dispensam reciprocamente; mais que isto, segundo a perspectiva, transitam entre decisão e regra. Não há fim para esta regressão; ela apenas é interrompida - em algum momento. Na visão de Luhmann, o pragmatismo se coloca a questão: a que isto nos leva? E assim liquida-a logo de saída. Outras tradições buscam um "direito vivo", um contrato social fundante, uma norma fundante do direito, a violência mítica e assim por diante. O direito natural pode levar adiante a regressão até... que algum deus lhe dê um camelo. De qualquer modo restará uma premissa primeira, assumida com alto grau de aleatoriedade e que não satisfaz as exigências operacionais erigidas sobre ela. 
O direito positivo, tradição na qual Luhmann se encontra, também tem o seu décimo segundo camelo - mas que só atende a função enquanto não for devolvido. Como pressuposto da decisão, o camelo passa a integrar o próprio sistema do direito e torna-se o garantidor da decisão que o torna dispensável. Este é para o autor o paradoxo do direito: não pode dispensar o camelo que é dispensável. Ou qual era mesmo a garantia da primeira regra jurídica positiva que, quando foi revogada, foi-o por uma regra que se apoiou nesta primeira regra?

O direito positivo, ainda segundo Luhmann, procura desfazer-se do paradoxo ao buscar amparo no pressuposto de que sua base seja a legislação, produzida por decisões políticas - portanto, noutro sistema funcional. A transferência lógica lhe é facilitada pela exigência basilar nos estados democráticos de direito de que a política, nas suas decisões formuladoras de regras, se atenha às regras do direito. Com esta "transferência" se cria uma assimetria que rompe a circularidade interna, mas com a condição de, logo em seguida, assegurar que a circularidade segue garantida. Assim cumpre-se que o sistema precisa encontrar fora de si os pressupostos sobre os quais opera e, simultaneamente, garantir sua absorção no sistema.

Cláusulas pétreas, princípios, direitos fundamentais são argumentações que trazem à tona outra situação paradoxal do direito em sociedades modernas: são fundamentações últimas para direitos e decisões que só se sustentam como legítimas na medida em que sua validade repousa unicamente sobre a decisão legal de sua positivação e que, por conseguinte, permanecem válidas até que outra decisão as altere ou revogue; sua revogabilidade as legitima - ainda que sejam pétreas. E neste transcurso se revela a dependência do direito face à argumentação, na medida em que na força do "melhor" argumento reside sua capacidade de produzir e reproduzir legitimidade, mais do que em qualidades intrínsecas que valores ou princípios que o embasam possam ter. Afinal, "a vontade soberana do legislador é a ausência de lei" (Ladeur, 2000, p. 185).

O centro desta argumentação, no entanto, é a constante remessa a decisões externas ao direito: decisões vindas da política, que, no estado de direito, assume a tarefa de legislar e, com isso, delimitar o espaço onde o que é e o que não é direito pode situar-se. Esta mesma política pode antecipar sua orientação pelas conseqüências e reduzir possibilidades para futuras decisões e inverter assim o jogo de instrumentalizações: enquanto o direito busca a política como amparo argumentativo para fundamentar suas decisões, a política pode instrumentalizar o direito deixando aos seu encargo a tomada final de decisões em que a ponderação das conseqüências esteja prescrita. Como bem observa Luhmann (2000, p. 45-52), a invenção do estado de direito tinha por objetivo substituir com ele o jusnaturalismo: eliminar externalidades bem como possibilitar maior generalização das expectativas e ganhar previsibilidade nas decisões. Direito e política formaram nele uma parceria em que um passa a ser o décimo segundo camelo para o outro. 
Procurar o fundamento do direito no direito e segundo regras do direito seria, pois, inócuo, segundo Luhmann. Pelo menos desde Kant está sistematizado o pressuposto de que no início do direito, como elo original vinculado à política, estaria a violência. $\mathrm{O}$ direito pode se apoiar nela como ultima ratio e, assim, mesmo face às eventuais ambigüidades para o observador, decidir todos os casos a decidir e ter respaldo para suas decisões. Isto ainda não precisa significar policiais armados nas ruas, atrás dos cidadãos, nas portas dos tribunais. A violência de que aqui se trata também é absorvida, "civilizada", para perpetuar-se estruturalmente dentro do sistema do direito. Na convicção de Luhmann, talvez não baste a observação interna para vê-la cumprindo seu papel. Daí a necessidade da observação de segunda ordem - externa como a sociologia jurídica.

2.

Os sociólogos, para Luhmann, via de regra não estão dispostos a aceitar acriticamente os juízos do sistema jurídico sobre direito/não-direito (Recht/ Unrecht). Quando observam e vêem quão pouco as bases dos processos judiciais correspondem à vida real, concluem que o direito só se mantém válido porquanto permanece oculta a abrangência em que ele próprio é violado. Para este observador, a técnica jurídica de tomar decisões com base no código binário direito/não-direito se apresenta como violação do mundo da vida. Não só que as palavras não têm o sentido que lhes é próprio no cotidiano; freqüentemente os partícipes acabam não compreendendo por que ganharam ou perderam a questão.

A queixa não é nova, diz Luhmann. O que se coloca, no entanto, é a questão: o que qualifica um sociólogo ou outro observador externo a dizer que algo não é direito ou que seja um direito injusto? A resposta está relacionada à observação do décimo segundo camelo - de modo a ver mais que o próprio sistema jurídico vê.

A operação basilar do direito mostra-se então em sua capacidade de transformar seu paradoxo fundante em uma contradição, o código binário (direito/não-direito) e de operar segundo ele. Segundo Luhmann, toda reflexão, toda produção textual do sistema se dedica a flanquear esta "camuflagem". Este modus operandi abrange e envolve todo o conjunto profissionalmente organizado de tomada de decisões que recebe petições, denúncias e outras demandas do entorno social, para sobre eles decidir - satisfazendo assim uma necessidade de decisões vinculantes.

O observador externo vê diferenciados neste sistema os aspectos normativo e cognitivo da prática jurídica. $O$ aspecto normativo trata da qualidade da norma que caracteriza o ato jurídico de decidir. Trata-se do fechamento operacional do sistema: toda operação que transmite uma qualidade normativa precisa pressupor e empregar qualidade normativa. Ela é contrafactual: antecipa um comportamento desejado e nisto manifesta a sua recusa ao aprendizado. Ela não se dispõe a corrigir as expectativas a 
partir das decepções. O aspecto cognitivo, por seu turno, envolve a consideração do ambiente social sob a ótica factual e histórica. É a face aprendente do sistema.

Há um risco para as normas se o sistema persistir unilateralmente na face normativa; num ambiente social em permanente transformação, expectativas petrificadas tornam inócua a procura do sistema para decisões vinculantes (como no código civil antigo a questão da virgindade feminina no casamento). Ele produz textos e argumentos que recodificam a realidade de tal modo que decisões possam ser tomadas com base em normas. Estas decisões são sempre também seleção de possibilidades - com a exclusão de outras possibilidades. Luhmann fala que são como bifurcações de um caminho: elas determinam quais serão as futuras possibilidades - inclusive qual a futura argumentação válida. Um exemplo deste tipo de bifurcação são as reiteradas decisões do Supremo Tribunal Federal que se restringem majoritariamente à formalidade, desprezando a materialidade, nas decisões sobre constitucionalidade das normas a ele submetidas. Em certa medida, o sistema sabota-se a sim próprio ao reduzir suas alternativas futuras numa trilha muito estreita.

Na observação a distância, a relação entre os aspectos normativo e cognitivo aparece como operações do tipo decisão e do tipo argumentação. Decisão e argumentação estão intimamente ligadas, mas cumprem funções bem definidas: decisões confirmam expectativas, argumentação abre o conjunto operativo do direito para o aprendizado. A decisão cumpre a função social do direito de produzir decisões vinculantes e é fechado em si; a argumentação transforma o mundo (externo e interno) segundo as necessidades do processo decisório. $\mathrm{Na}$ argumentação são captados estímulos do ambiente social no qual o direito está presente, e que podem vir a ser fundamento para futuras decisões. Luhmann define o aprendizado como a abertura cognitiva do sistema social - no caso, do direito.

Nesta operação de transformação do mundo segundo as necessidades do processo decisório, o ambiente social é expropriado de suas questões, que passam a ser questões jurídicas. A tradição da sociologia crítica do direito tem centrado seu discurso nesta expropriação. O décimo segundo camelo seria aqui uma espécie de cavalo de Tróia invertido. Na tradição positivista, inclusive em sua variante sistêmica (cf. Teubner e Zumbamsen, 2000), a transformação é festejada; o pecado original do direito transformase em sua virtude cardinal. Na sociedade há muitos conflitos, e a grande maioria deles são resolvidos por mecanismos e instituições fora do sistema jurídico. Boaventura de Sousa Santos e colegas (1996) descrevem esta seletividade como uma pirâmide de letigiosidade. Sorte do direito que sempre ainda sobram alguns, talvez os mais difíceis, que não encontram solução antes de chegarem ao que aqueles autores denominam "tribunais". $\mathrm{Na}$ medida em que a sociologia crítica do direito tiver razão, eles precisam ser expropriados da sociedade, transformados mediante uma linguagem altamente artificial e alienante, distorcedora. 
Por si só o Direito não consegue desenvolver empatia capaz de compreender os conflitos "lá fora". Ao invés disso ele pode transformá-los em questões de direito a ponto de se tornarem decidíveis pelo direito - operação que os distanciará do conflito original. O camelo do Cadi não é igual aos outros camelos como também a questão jurídica é diferente da questão social que lhe deu origem. O direito, segundo Teubner, de forma alguma é o meio adequado para solucionar questões interpessoais e satisfazer as partes. Mediação, negociação e outros instrumentos são possivelmente mais adequados para isto, especialmente quando se atêm às expectativas de comportamento cristalizadas em normas sociais. O direito não decide sobre o conflito que deu origem à questão jurídica; ele decide sobre sua própria ficção.

Feita a transformação da questão social numa questão jurídica, tomada eventualmente a decisão "cabível", pode-se então finalmente devolver o camelo? Não, de forma alguma dirão tanto Teubner como Luhmann: é ele que garante que o sistema operacionalmente fechado se mantenha aberto. Precisamente a recepção de estímulos externos (camelos) através da argumentação jurídica, permite que a recusa de aprendizado típica das decisões seja complementada pela abertura ao aprendizado - típico da argumentação jurídica. A construção das ficções jurídicas é o modo como o sistema jurídico evolui. O nome técnico que a teoria sistêmica dá a esta operação é o reentry. Assim, a circularidade do sistema evolui com o aprendizado resultante do estímulo advindo do ambiente. Sem estes estímulos, em que o não-direito se torna direito, o sistema permaneceria uma eterna redundância. Mas o direito enquanto tal não pode se perguntar de onde vem o décimo segundo camelo nem como chegou até aqui.

Assim, a alienação feita pelo Direito abre possibilidades para a produção social de sentido, que rompe os sulcos nos quais a produção de decisões com base em expectativas normativas se fixou. Teubner vê paralelos entre a sociologia jurídica e a literatura, por exemplo, nesta criação de sentidos inesperados, produtivos. Com isso, segundo este autor, para o observador externo, o sistema jurídico apresenta dois circuitos comunicativos distintos: um como concatenação de decisões, tendente a estabilizar expectativas, e outro como concatenação de argumentos, tendente a provocar evolução do sistema pelo aprendizado. São circuitos paralelos, intimamente relacionados entre si, sem que contudo um possa determinar o outro. Precisamente porque a argumentação recepciona os estímulos do ambiente social - faz o reentry -, transformando conflitos sociais em questões jurídicas, ela cria alternativas de decisão. A decisão segue necessária, mas suas alternativas estão re-formuladas. Deste modo há uma co-variação entre as estruturas sociais em permanente mudança e as próprias alternativas de decisão do direito. Assim, a expropriação referida acima pode não ser de todo ruim. Em relação à situação individual, é verdade, ela provoca distanciamento; para o sistema jurídico ela representa o fim da redundância, a possibilidade de evolução, de adaptação de suas estruturas. O pressuposto deste ganho social, contudo, 
é que, nas múltiplas bifurcações possíveis, o próprio direito opte pela assimilação dos estímulos que lhe são disponibilizados constantemente pelo entorno social - e quanto mais diversificadas estas absorções dentro do leque de possibilidades, mais ganhos cognitivos e mais legitimidade podem resultar no final de cada etapa processual.

Luhmann aponta para a "orientação pelas conseqüências" (Folgenorientierung) como uma das principais formas de inserir assimetrias que rompem com a circularidade interna. Neste modo de proceder, busca-se antever e avaliar supostas conseqüências da decisão, para inseri-las como fundamentação legítima da decisão presente. Uma previsão de futuro assume o lugar da avaliação de fatos e circunstâncias, o que, segundo Luhmann, "é tanto mais fácil, quanto o futuro ainda não se constitui como conflito" (2000, p. 33).

Esta prática, passível de ser interpretada como uma abertura cognitiva, suscita várias questões como a previsibilidade deste futuro, a possibilidade de outras conseqüências importantes e não consideradas modificarem a avaliação que embasou a decisão e a incidência da decisão sobre as circunstâncias futuras ao modo das profecias autocumpridas. Se por um lado parece compreensível que a tomada de decisões no âmbito jurídico seria inconseqüente se ela "por princípio e sempre" fosse levada a cabo "sem levar em conta as conseqüências", por outro, a orientação pelas conseqüências dá às decisões uma base frágil e insegura como areia movediça. Para Luhmann, "isto leva à conclusão de que a orientação pelas conseqüências seja necessária e impossível" (ibid.).

Ainda que a introdução deste décimo segundo camelo no processo decisório não seja tão dramática no cotidiano da operação do direito como o é para lógica, ela expõe fragilidades do sistema jurídico. Ao cidadão comum, o "aplicador normal do direito" (Luhmann), não é facultado orientar-se pelas conseqüências de sua decisão no âmbito do objeto da decisão; este arbítrio lhe foi tolhido pelo legislador. Diante da interdição do consumo de bebidas alcoólicas para motoristas, por exemplo, ele não pode avaliar riscos de acidente e, dentro de uma margem de segurança por ele considerada confortável, optar por dirigir após ingerir este tipo de bebida. Resta-lhe como âmbito para orientar-se pelas conseqüências apenas o poder de dissuasão da probabilidade de ser punido, da dificuldade de livrar-se de eventual punição e da magnitude desta. Luhmann chama a atenção que "através da proclamação e intensivação da orientação pelas conseqüências, reforça-se dentro do sistema jurídico a diferença entre o serviço profissional-organizado de tomada de decisões e a orientação comum pelo direito" (2000, p. 34). Se a postura utilitarista diante do direito se generalizar, deixam de existir expectativas normativas e, no limite, se dissolve o estado de direito; para que não se generalize, o "décimo segundo camelo" precisa ficar reservado como privilégio funcional de poucos operadores. Mas esta clivagem entre operadores profissionais do direito e cidadãos não vinculados profis- 
sionalmente ao mundo jurídico subverte gradativamente a unicidade da orientação pela lei e mina a legitimidade do direito; ela afeta visceralmente a democracia.

Há muitos conflitos no ambiente social demandando decisões do sistema jurídico. Provavelmente nem todos tenham o mesmo potencial de estímulo à evolução do sistema. Os direitos sociais são -ou pelo menos foram por algumas décadas - um destes complexos externos produtores de conflitos, legitimadores de governos, de políticas e de instituições jurídicas, mas difíceis de serem materializados dentro da lógica prevalente (cf. Flickinger, 2003; Sobottka, 2006). Reivindicações que se apóiam na dignidade da pessoa humana, justamente por sua diversidade, expandem em muito o leque de possibilidades (cf. Tiedemann, 2006). Seu potencial para catalizar os processos internamente ao direito depende da capacidade dos próprios operadores do direito de acolherem cognitivamente as ofertas do entorno social que poderiam municiar ad nauseam a argumentação jurídica e significar aprendizado e evolução para o sistema jurídico. Esta abertura, no entanto, também confronta o direito com outro dilema: os conflitos que lhe são colocados advêm via de regra de interpretações de princípios fundamentais ou de derivações deles, que geraram expectativas divergentes e, no limite, excludentes.

\section{3.}

$\mathrm{Na}$ constituição brasileira, a dignidade da pessoa humana é colocada como um dentre cinco fundamentos da república. Por que o deveria, isto o autor não explicita. Mas eles não são necessariamente compatíveis entre si. Situações em que o estado considere a soberania superior à dignidade do indivíduo são corriqueiras. De modo similar, o valor social do trabalho e da livre iniciativa, cada qual por diferentes razões, têm alto potencial de colisão com a dignidade.

Comparato (1998) argumenta que a dignidade da pessoa humana não deveria ser apenas um entre outros, mas o fundamento principal. Mesmo que o fosse, uma ampla gama de situações se colocam em que direitos diferentes derivados da dignidade ou direitos de diferentes pessoas igualmente derivados da dignidade colidam (cf. Alexi, 1997; discussão em: Sarlet, 2002). A solução mais amplamente aceita é a da ponderação. Contudo, que é a medida legítima desta ponderação? Não se necessita, neste caso, justamente um critério externo para dosar adequadamente esta ponderação?

A grande diferença entre a discussão provocada por Luhmann com sua reflexão sobre o décimo segundo camelo - e sua compreensão da sociologia jurídica - e a visão dos defensores da ponderação de princípios é que Luhmann sabe exatamente quando e para que o direito busca auxílio externo; ironicamente, o texto intitulado $A$ devolução do décimo segundo camelo revela que seu autor não consegue decidir o que fazer com aquele auxílio. 
Talvez porque os teóricos sistêmicos - em menor grau Luhmann do que Teubner - vêem na perspectiva do direito a questão da fundamentação como em princípio resolvida, merecendo os casos residuais a continuidade da reflexão, sem potencial para questionar o conjunto dos procedimentos; o recurso ao décimo segundo camelo não é desprezível, mas não lhes parece afetar gravemente a auto-compreensão que o sistema tem e cultiva de si próprio.

Há, no entanto, duas visões mais críticas que merecem ser aqui referidas: de uma parte, a de Marcelo Neves (2004), dentro da tradição da teoria sistêmica, e de outra a já mais antiga reflexão de Franz Hinkelammert (1985). Ambos colocam em dúvida a possibilidade de que estas soluções mantenham o direito legitimamente no estado democrático de direito.

Neves (2004; mais aprofundado em 2006) coloca em dúvida a validade do modelo teórico que embasa a teoria sistêmica moderna na medida em que ele depende tando do fechamento operacional como da abertura cognitiva. Em especial em tipos de sociedade pelo autor definidas como de modernidade periférica, conceito para o qual o Brasil serve como protótipo, haveria possibilidades, efetivamente atualizadas, de que as influências externas não sejam acolhidas no interior do sistema como aprendizado, como resultado da abertura cognitiva, mas como deformação da comunicação que tem como resultado final o fim do fechamento operacional, ou seja, a heteronomia. Seleções privilegiadas comunicadas pelo meio social, resultantes "do entrelaçamento dos códigos de preferência [...] e dos critérios ou programas dos diversos campos de comunicação" resultariam em "uma guerra hobbesiana entre os diversos domínios da ação, de tal maneira que a complexidade social permanece insuficientemente organizada ou deficientemente estruturada" (2004, p. 148). Com isso, o direito, por exemplo, incapaz de delimitar suas fronteiras em relação ao ambiente social, leva a que as expectativas normativas a ele correlatas se orientem antes por áreas como a economia e a política que pelo direito.

As conseqüências disto na sociedade podem afetar não só o bom funcionamento de um sistema em particular, mas o conjunto da sociedade. Os conceitos de subintegração e sobreintegração se referem a situações onde o acesso aos seus direitos é desproporcionalmente menor que a cobrança dos deveres para os primeiros e, inversamente, para os segundos. Um sistema assim dificilmente pode servir de sustentáculo para um estado democrático de direito, com seu corolário de princípios declarados como fundamentais. O próprio autor chama a atenção para o fato que neste texto o recurso externo buscado por Luhmann para sua reflexão é uma metáfora do universo religioso, não europeu e pré-moderno.

Mais contundente em sua crítica, feita no contexto da pretensão de realização plena dos direitos humanos, é a de Hinkelammert (1985). Este autor começa sua reflexão chamando a atenção para a abertura do conjunto de direitos humanos, ao qual mais e mais se agregam reivindicações 
específicas reconhecidas como direito universal. Isto leva a que "nunca y em ningún lugar, todos estos derechos pueden ser cumplidos a cabalidad. Siempre hace falta limitarlos en algún sentido." O cumprimento de um direito pode interferir no cumprimento de outro; quanto mais irrestrita a pretensão de cumprir um, mais restrita será a possibilidade do cumprimento de outros.

Como resultado, surge a necessidade de hierarquizar os direitos; em caso de algum conflito, alguns serão preteridos em relação aos outros. No topo desta hierarquia aparecerá resultante um último direito fundamental "a partir del cual todos los otros son interpretados como secundarios, en el sentido que tienen que ser interpretados o limitados en función de la vigencia de este derecho clave". Para Hinkelammert, o que distinguirá as diferentes formas de democracia, mais do que tudo será resultante do grau em que se apóiam em princípios de hierarquização diferentes. O constante processo de preterimento de um direito em relação a outro pode levar, no limite, a que alguns direitos acabem realizados como seu inverso. Uma esfera típica seria a do poder público que mata para defender a vida.

Assim, a dignidade da pessoa humana parece surgir com pretensão de ocupar o lugar funcional de um novo direito fundamental, candidato a encabeçar a hierarquia de todos os direitos, a figurar como o décimo segundo camelo que assegura a operacionalidade do direito e o fechamento operacional do sistema jurídico. Mas provavelmente é cedo para festejar esta entronização. Não porque se constata que lhe faltam qualidades intrínsecas - estas não estão no centro da questão; o lugar que lhe está destinado não comporta um princípio fundamental com esta transcendência. Hinkelammert argumenta que o direito que se torna o princípio de hierarquização diz respeito à distribuição dos bens materiais. De modo equiparável, Neves demonstra como a política e em especial a economia intervêm heteronomamente no direito e o moldam até acomodá-lo a interesses alheios ao mundo jurídico. Os próprios defensores da dignidade humana como princípio basilar (cf. textos em Sarlet, 2005; Tiedemann, 2006) admitem a necessidade e a possibilidade de que ele colida com outros princípios e necessite ser relativizado; se os direitos dele deriváveis são numerus clausus ou quantitativamente abertos, se o princípio é suficientemente concreto ou não para derivar direitos específicos resta de menor importância. Mas talvez ele seja mesmo um equivalente funcional do décimo segundo camelo como Luhmann o descreve - com todas as suas ambigüidades e debilidades.

\section{Referências}

ALEXY, R. Teoria de los derechos fundamentales. Madrid: Centro de Estúdios Constitucionales, 1997.

BRASIL. Constituição da República Federativa do Brasil. http://www.senado.gov.br/sf/legislacao/ const/. (jul. 2008). 
COMPARATO, F. K. Fundamento dos Direitos Humanos. In: Cultura dos direitos humanos. São Paulo: Editora Ltr, 1998. p. 53-74. Disponível em: www.iea.usp.br/iea/artigos/comparatodireitos humanos.pdf

FLICKINGER, Hans-Georg. Em nome da liberdade: elementos da crítica ao liberalismo contemporâneo. Porto Alegre: EDIPUCRS, 2003.

HÄBERLE, P. A dignidade humana como fundamento da comunidade estatal. In: SARLET, Ingo W. Dimensões da dignidade: ensaios de filosofia do direito e direito constitucional. Porto Alegre: Livraria do Advogado, 2005. p. 89-152.

HINKELAMMERT, F. J. Democracia y derechos humanos. Pasos, v. 1, 1985, p. 12-15.

. Democracia y totalitarismo. San José, DEI, 1987.

KANT, I. Grundlegung der Metaphysik der Sitten. In: Immanuel Kant: Werke in zwölf Bänden. Herausgegeben von Wilhelm Weischedel. Frankfurt am Main: Suhrkamp, 1977, 1974. v. 7. (CD-Rom). Português: Fundamentação da metafísica dos costumes. Tradução Paulo Quintela. Lisboa: Edições 70, 2002.

Resposta à pergunta: que é o iluminismo. In: Paz perpétua e outros opúsculos. Lisboa: Edições 70, 1988. p. 11-19.

LADEUR, Karl-Heinz. Das selbstreferenzielle Kamel: Die Emergenz des modernen autonomen Rechts. In: G. TEUBNER. Die Rückgabe des zwölften Kamels: Niklas Luhmann in der Diskussion über Gerechtingkeit. Stuttgart: Lucius und Lucius, 2000. p. 177-188.

NEVES, M. E se faltar o décimo segundo camelo? Do direito expropriador ao direito invadido. In: ARNAUD, André-Jean; LOPES JR., Dalmir. Niklas Luhamnn: do sistema social à sociologia jurídica. Rio de Janeiro: Lumen Juris, 2004. p. 145-173.

. Entre Têmis e Leviatã: uma relação difícil. São Paulo, Martins Fontes, 2006.

SANTOS, B. de S. et al. Os tribunais nas sociedades contemporâneas. Revista Brasileira de Ciências Sociais. v. 11, n. 30, 1996, p. 29-62.

SARLET, I. W. Dignidade da pessoa humana e direitos fundamentais na Constituição Federal de 1988. Porto Alegre: Livraria do Advogado, 2002.

. (Org.). Dimensões da dignidade: ensaios de filosofia do direito e direito constitucional. Porto Alegre: Livraria do Advogado, 2005.

SOBOTTKA, E. A. Por que se faz políticas sociais no Brasil? Notas sobre estratégias de legitimação nos últimos dois governos federais. Civitas, v. 6, n. 1, p. 79-93, jan./jun. 2006.

TEUBNER, G.; ZUMBANSEN, P. Rechtsverfremdungen: Zum gesellschaftlichen Mehrwert des zwölften Kamels. In: TEUBNER, Günther. Die Rückgabe des zwölften Kamels: Niklas Luhmann in der Diskussion über Gerechtingkeit. Stuttgart: Lucius und Lucius, 2000. p. 189-215.

TIEDEMANN, P. Der Begriff der Menschenwürde: Eine Anfrage an die Sozialphilosophie. e-Journal Philosophie der Psychologie. Frankfurt am Main, out. 2006. Disponível em: http:// www.jp.philo.at/texte/TiedemannP1.pdf 